\title{
A Novel User Utility Score for Diabetes Management Using Tailored Mobile Coaching: Secondary Analysis of a Randomized Controlled Trial
}

\author{
Min-Kyung Lee ${ }^{1}$, MD; Da Young Lee ${ }^{2}$, MD; Hong-Yup Ahn ${ }^{3}$, MD, PhD; Cheol-Young Park ${ }^{4}, \mathrm{MD}, \mathrm{PhD}$ \\ ${ }^{1}$ Division of Endocrinology and Metabolism, Department of Internal Medicine, Myongji Hospital, Hanyang University College of Medicine, Gyeonggi-do, \\ Republic of Korea \\ ${ }^{2}$ Division of Endocrinology and Metabolism, Department of Internal Medicine, Korea University College of Medicine, Seoul, Republic of Korea \\ ${ }^{3}$ Department of Statistics, Dongguk University-Seoul, Seoul, Republic of Korea \\ ${ }^{4}$ Division of Endocrinology and Metabolism, Department of Internal Medicine, Kangbuk Samsung Hospital, Sungkyunkwan University School of \\ Medicine, Seoul, Republic of Korea
}

\section{Corresponding Author:}

Cheol-Young Park, MD, PhD

Division of Endocrinology and Metabolism

Department of Internal Medicine

Kangbuk Samsung Hospital, Sungkyunkwan University School of Medicine

29 Saemunan-ro, Jongno-gu

Seoul, 03181

Republic of Korea

Phone: 82220011869

Email: cydoctor@chol.com

\section{Abstract}

Background: Mobile health applications have been developed to support diabetes self-management, but their effectiveness could depend on patient engagement. Therefore, patient engagement must be examined through multifactorial tailored behavioral interventions from an individual perspective.

Objective: This study aims to evaluate the usefulness of a novel user utility score (UUS) as a tool to measure patient engagement by using a mobile health application for diabetes management.

Methods: We conducted a subanalysis of results from a 12-month randomized controlled trial of a tailored mobile coaching (TMC) system among insurance policyholders with type 2 diabetes. UUS was calculated as the sum of the scores for 4 major core components (range 0-8): frequency of self-monitoring blood glucose testing, dietary and exercise records, and message reading rate. We explored the association between UUS for the first 3 months and glycemic control over 12 months. In addition, we investigated the relationship of UUS with blood pressure, lipid profile, and self-report scales assessing diabetes self-management.

Results: We divided 72 participants into 2 groups based on UUS for the first 3 months: UUS:0-4 (n=38) and UUS:5-8 ( $n=34$ ). There was a significant between-group difference in glycated hemoglobin test $\left(\mathrm{HbA}_{1 \mathrm{c}}\right)$ levels for the 12-months study period $(P=.011)$. The $\mathrm{HbA}_{1 \mathrm{c}}$ decrement at 12 months in the UUS:5-8 group was greater than that of the UUS:0-4 group [-0.92 (SD $1.24 \%$ ) vs -0.33 (SD 0.80\%); $P=.049$ ]. After adjusting for confounding factors, UUS was significantly associated with changes in $\mathrm{HbA}_{1 \mathrm{c}}$ at 3, 6, and 12 months; the regression coefficients were -0.113 (SD 0.040; $P=.006$ ), -0.143 (SD 0.045; $P=.002$ ), and -0.136 (SD 0.052; $P=.011$ ), respectively. Change differences in other health outcomes between the 2 groups were not observed throughout a 12-month follow-up.

Conclusions: UUS as a measure of patient engagement was associated with changes in $\mathrm{HbA}_{1 \mathrm{c}}$ over the study period of the TMC system and could be used to predict improved glycemic control in diabetes self-management through mobile health interventions.

Trial Registration: ClinicalTrial.gov NCT03033407; https://clinicaltrials.gov/ct2/show/NCT03033407

(JMIR Mhealth Uhealth 2021;9(2):e17573) doi: $\underline{10.2196 / 17573}$ 


\section{KEYWORDS}

type 2 diabetes; mobile applications; diabetes management; patient engagement

\section{Introduction}

\section{Background}

The rate of diabetes has been steadily increasing over the past few decades [1,2], and its associated complications are major causes of morbidity and mortality [3] that lead to substantial economic loss through direct medical costs [4]. To prevent diabetes complications and decrease economic burden, multifaceted professional interventions are needed $[5,6]$. Successful treatment of diabetes includes patient self-management such as lifestyle intervention [7,8]. Clinical trials have shown that effective lifestyle modifications can substantially reduce the risk of developing diabetes and improve patient health outcomes $[9,10]$.

Digital health technology-based tools have been developed to assist in diabetes self-management [11]. Due to increasing evidence for the efficacy of digital health tools for improving glycated hemoglobin $\left(\mathrm{HbA}_{1 \mathrm{c}}\right)$ levels and other diabetes-related outcomes, both the 2017 National Standards for Diabetes Self-management Education and Support [12] and the 2019 American Diabetes Association Standards of Medical Care [13] recommend including technology-based solutions to deliver diabetes care and education. Mobile platforms and health applications are increasingly being implemented as useful tools for patients and health care providers [14] and play a role in supporting diabetes self-management by sharing data with providers and providing minimal data analysis, interpretation, and guidance to patients [15]. However, the effectiveness of digital health tools to improve diabetes outcomes could depend on patient engagement in the beginning, such as proper blood glucose testing, medication adherence, adoption of a healthy diet and physical activity, and advice-sharing text messages [16]. Patient engagement is increasingly regarded as a crucial factor in diabetes management [17]. Therefore, patient engagement must be examined through multifactorial tailored behavioral interventions because of the variability in self-management capability.

A 12-month randomized clinical trial demonstrating the effectiveness of tailored mobile coaching (TMC) on diabetes management among policyholders with type 2 diabetes was previously reported [18]. TMC is a mobile health care system in which the intensive coaching from health care providers and the self-application of patients are organically connected. The effectiveness of the TMC system can vary depending on patient engagement in diabetes self-management. In this study, we conduct a subanalysis of the TMC study to evaluate the relationship between patient engagement and diabetes-related health outcomes. We developed a novel user utility score (UUS) consisting of 4 major components of blood glucose testing [19], dietary habits [20], exercise [21], and message reading [22] as a tool to measure patient engagement.

\section{Objectives}

This study examines the usefulness of UUS as a tool to measure patient engagement by using a mobile health application for diabetes management among policyholders with type 2 diabetes. The primary aim of this paper is to determine whether UUS for the first 3 months results in improved glycemic control over a 12-month follow-up period among policyholders with type 2 diabetes. In addition, we investigate the relationship of UUS with blood pressure, lipid profile, and diabetes self-management.

\section{Methods}

\section{Ethics Approval and Consent to Participate}

All participants provided written informed consent before any study procedures were started. The trial protocol was reviewed and approved by the institutional review board of Kangbuk Samsung Hospital (KBS12089) and was conducted in accordance with the Helsinki Declaration of 1975.

\section{Study Population and Design}

This study was conducted with Korean policyholders with type 2 diabetes recruited from Samsung Fire and Marine Insurance (Seoul, South Korea) from October 2014 to December 2015. This study was an open-label, randomized controlled trial to evaluate the effectiveness of the TMC system provided by Kangbuk Samsung Hospital, Seoul, Korea. Participants were randomly assigned into an intervention group and a control group. During a 6-month assessment period, the intervention group received TMC for diabetes management via a mobile app, whereas the control group maintained their usual diabetes care. After 6 months, the second 6-month period of the study was conducted and included the subjects who agreed to participate. Identification and recruitment of patients have been described in the previous study [18].

We conducted a subanalysis of results from the TMC group over 12 months. During the first 6-month period, 72 participants were assessed, and 54 participants were followed up with in the second 6-month period. There were 18 participants with missing values at 12 months. We analyzed detailed data uploaded to the mobile app Switch (Huraypositive Inc) and developed a novel UUS. Participants who received TMC were divided into 2 groups based on UUS for the first 3 months. We evaluated the relationship between UUS as an index of patient engagement and glycemic control for diabetes management.

\section{Tailored Mobile Coaching (TMC) System and the Switch App}

The TMC system is a medical service to support diabetes self-management through bidirectional communication between health care providers and patients by sharing data uploaded to the mobile app Switch without any additional equipment for data transmission or a web portal for users. Users of the mobile app could upload measurement data such as self-monitoring of blood glucose, blood pressure, and body weight, along with their lifestyle, including dietary records, physical activities, and 
medical information. Care managers sent messages to provide appropriate educational information to patients. Participants received regular mobile messages and were allowed to communicate with providers via the Switch app. Care managers analyzed the transmitted records and sent messages on the secured website twice a week. The message content included notifications for behavioral recommendations, diabetes education, and individualized advice. At any time, users could check their data by logging into the Switch app, where they could obtain information on diabetes and other metabolic diseases. Details about the TMC system and Switch app have been described in the previous study [18].

\section{UUS (User Utility Score)}

UUS was calculated as the sum of the scores for 4 core components: frequency (days) of self-monitoring of blood glucose testing, dietary and exercise records, and message reading rate (percent). We divided the data of each component for the first 3 months into tertiles: first (T1), second (T2), and third tertiles (T3) that were 0-33, 34-75, and 76-91 days for self-monitoring of blood glucose; 0-3, 4-30, and 31-91 days for dietary records; $0-37,38-81$, and 82-91 days for exercise records; and 0\%-73\%, 74\%-97\%, and 98\%-100\% for message reading rates, respectively. $\mathrm{T} 1, \mathrm{~T} 2$, and $\mathrm{T} 3$ were scored as 0,1 , and 2 points, respectively, and the range of UUS was 0-8.

To validate UUS accuracy using the current dataset, we used another dataset from an outpatient clinic at Kangbuk Samsung Hospital from June 2012 to March 2013 [23]. The prospective clinical study evaluated the effectiveness of mobile health-based diabetes self-management [23]. The participants from the intervention group $(n=39)$ were used as a sample of the training set. We found that UUS was associated with a change in $\mathrm{HbA}_{1 \mathrm{c}}$ at 6 months; the regression coefficient was -0.078 (SD 0.037; $P=.04)$.

\section{Measurements}

The primary outcome was changes in $\mathrm{HbA}_{1 \mathrm{c}}$ over the 12-month study period. The secondary outcomes were diabetes-related health outcomes and diabetes self-management. On the first visit, participants completed a self-administered questionnaire regarding demographic characteristics, social history, and other medical conditions. Smoking and drinking habits were categorized as noncurrent or current. Body mass index (BMI) was calculated as weight in kilograms divided by the square of height in meters. Blood pressure was measured in a seated position after 5 minutes of rest. Blood samples were obtained after overnight fasting to measure $\mathrm{HbA}_{1 \mathrm{c}}$, total cholesterol, triglycerides, high-density lipoprotein (HDL) cholesterol, and low-density lipoprotein (LDL) cholesterol. The Korean version of the Summary of Diabetes Self-Care Activities (SDSCA) questionnaire [24] and the Korean version of the Appraisal of Diabetes Scale (ADS) [25] were applied to evaluate diabetes self-management. The SDSCA includes items assessing diet (general and specific), exercise, blood glucose testing, foot care, and smoking over the past week; higher scores indicate better self-care behaviors [26]. The ADS is a stable measure of diabetes-related appraisal, with a smaller total score indicating a more positive appraisal [27]. Clinic or laboratory tests were repeated at baseline, 3, 6, and 12 months. A self-administered questionnaire was obtained at baseline and at 6-and 12-month follow-up evaluations.

\section{Statistical Analyses}

Participants were divided into 2 groups according to the median value of UUS. The study outcomes of both groups were compared using the Student $t$ test for continuous variables and a chi-square test for categorical variables. Data were expressed as a mean and standard deviation or as a number (proportion). Repeated-measures analyses of variance (ANOVA) were used to monitor differences in $\mathrm{HbA}_{1 \mathrm{c}}$ between the 2 groups over a 12 -month period. In cases of missing follow-up visit (12 months) data, the last observation carried forward (LOCF) imputation method was used. Exploratory data analysis is used to investigate changes in $\mathrm{HbA}_{1 \mathrm{c}}$ from baseline at 3, 6, and 12 months for both groups. To assess an association of UUS with changes in $\mathrm{HbA}_{1 \mathrm{c}}$, multivariable linear regression analyses were used. Model 1 was adjusted for age and sex. Model 2 was adjusted for age, sex, BMI, systolic blood pressure, LDL, $\mathrm{HbA}_{1 \mathrm{c}}$ at baseline, and diabetes duration. Model 3 was adjusted for age, sex, BMI, systolic blood pressure, $\mathrm{LDL}, \mathrm{HbA}_{1 \mathrm{c}}$ at baseline, diabetes duration, cigarette smoking, alcohol consumption, and ADS. The Bonferroni correction was then used to perform multiple comparisons between the 3 points of time. To identify the decrease amount in $\mathrm{HbA}_{1 \mathrm{c}}$, the reduction rate of $\mathrm{HbA}_{1 \mathrm{c}}$ was evaluated. The $\mathrm{HbA}_{1 \mathrm{c}}$ reduction rate was equal to the difference in $\mathrm{HbA}_{1 \mathrm{c}}$ divided by baseline $\mathrm{HbA}_{1 \mathrm{c}}$ value times $100 \%$. Linear regression analysis was performed to test the relationship between the $\mathrm{HbA}_{1 \mathrm{c}}$ reduction rate and UUS. A $P$ value <.05 was considered statistically significant. All data were analyzed using SPSS (version 18.0; IBM Corp).

\section{Prior Presentation and Data Availability}

These data were presented at the American Diabetes Association 77th Scientific Session. The data used or analyzed during this study are available from the Samsung Fire and Marine Insurance Company; however, restrictions apply to the availability of these data, which were used under the license of this study. Data are available from the authors upon reasonable request and with the permission of Samsung Fire and Marine Insurance Company.

\section{Results}

\section{Participant Characteristics}

Participants were divided into 2 groups, UUS:0-4 and UUS:5-8, based on the UUS for the first 3 months. At 3 and 6 months, 72 participants were assessed: 38 participants in the UUS:0-4 group and 34 participants in the UUS:5-8 group. At 12 months, 54 participants were followed up with: 23 participants in the UUS:0-4 group and 31 participants in the UUS:5-8 group. Table 1 shows the baseline characteristics of the 2 groups. There were no significant differences between groups with regard to age, sex, BMI, blood pressure, $\mathrm{HbA}_{1 \mathrm{c}}$, LDL cholesterol levels, diabetes duration, cigarette smoking, alcohol consumption, and SDSCA and ADS scores. The mean $\mathrm{HbA}_{1 \mathrm{c}}$ level was $8.07 \%$ (SD $1.23 \% ; 65 \mathrm{mmol} / \mathrm{mol}$ ) in the UUS:0-4 group and $8.20 \%$ (SD $1.69 \% ; 66 \mathrm{mmol} / \mathrm{mol})$ in the UUS:5-8 group $(P=.69)$. 
Table 1. Baseline characteristics of participants divided into 2 groups based on user utility scores (UUS; $n=72$ ).

\begin{tabular}{|c|c|c|c|}
\hline Characteristic & UUS:0-4 ( $\mathrm{n}=38)$ & UUS:5-8 $(n=34)$ & $P$ value $^{\mathrm{a}}$ \\
\hline Age in years, mean $(\mathrm{SD})$ & $50.58(8.52)$ & $52.38(7.13)$ & .34 \\
\hline Gender, n (\%) & & & .40 \\
\hline Male & $21(53.8)$ & $21(63.6)$ & \\
\hline Female & $17(46.2)$ & $13(36.4)$ & \\
\hline Body mass index $\left(\mathrm{kg} / \mathrm{m}^{2}\right)$, mean (SD) & $26.34(3.19)$ & $25.71(3.42)$ & .42 \\
\hline Systolic blood pressure (mmHg), mean (SD) & $137.29(16.54)$ & $136.88(15.50)$ & .92 \\
\hline Diastolic blood pressure (mmHg), mean (SD) & $87.34(11.74)$ & $86.68(8.73)$ & .79 \\
\hline $\mathrm{HbA}_{1 \mathrm{c}}{ }^{\mathrm{b}} \%$, mean $(\mathrm{SD})$ & $8.07(1.23)$ & $8.20(1.69)$ & .69 \\
\hline Total cholesterol (mg/dL), mean (SD) & $165.18(25.22)$ & $175.52(39.05)$ & .20 \\
\hline Triglyceride (mg/dL), mean (SD) & $153.31(61.55)$ & $139.73(60.75)$ & .35 \\
\hline HDL cholesterol (mg/dL), mean (SD) & $46.05(9.12)$ & $48.85(13.29)$ & .30 \\
\hline LDL cholesterol (mg/dL), mean (SD) & $88.40(24.81)$ & $98.54(34.52)$ & .17 \\
\hline Current smoker, n (\%) & $13(33.3)$ & $6(18.2)$ & .15 \\
\hline Current alcohol drinker, n (\%) & $15(38.5)$ & $15(45.5)$ & .55 \\
\hline Diabetes duration in years, mean (SD) & $7.28(3.71)$ & $7.23(6.49)$ & .81 \\
\hline Insulin injection, $\mathrm{n}(\%)$ & $8(20.5)$ & $8(24.2)$ & .70 \\
\hline Antihypertensive medication, $\mathrm{n}(\%)$ & $16(41)$ & $11(33.3)$ & .50 \\
\hline Antidyslipidemic medication, $\mathrm{n}(\%)$ & $24(61.5)$ & $14(42.4)$ & .11 \\
\hline \multicolumn{4}{|c|}{ Summary of Diabetes Self-Care Activities (SDSCA) questionnaire, mean (SD) } \\
\hline Diet total & $10.47(5.47)$ & $11.68(6.62)$ & .40 \\
\hline Exercise & $5.82(4.13)$ & $6.26(3.86)$ & .64 \\
\hline Blood glucose testing & $3.00(4.23)$ & $4.94(5.27)$ & .09 \\
\hline Foot care & $3.58(3.94)$ & $3.09(3.53)$ & .58 \\
\hline Appraisal of Diabetes Scale (ADS) total, mean (SD) & $19.76(4.27)$ & $19.18(4.54)$ & .57 \\
\hline
\end{tabular}

${ }^{\mathrm{a}} P$ values were derived from the Student $t$ test or Pearson chi-square test.

${ }^{\mathrm{b}} \mathrm{HbA}_{1 \mathrm{c}}$ : glycated hemoglobin.

\section{UUS and Changes in $\mathbf{H b A}_{1 \mathrm{c}}$}

Figure 1 depicts mean $\mathrm{HbA}_{1 \mathrm{c}}$ levels for the 12-month study period in the UUS:0-4 group and UUS:5-8 group. Significant differences were observed in the improvement of $\mathrm{HbA}_{1 \mathrm{c}}$ within each group $(P<.001)$ and between groups $(P=.011)$ by repeated-measures ANOVA. The UUS:5-8 group was significantly reduced compared with the UUS:0-4 group at 3, 6 , and 12 months in intention-to-treat analyses (LOCF). Table
2 shows changes in $\mathrm{HbA}_{1 \mathrm{c}}$ levels from baseline at 3, 6, and 12 months for both groups. At 12 months, the mean change in $\mathrm{HbA}_{1 \mathrm{c}}$ was $-0.92(\mathrm{SD} 1.24 \%$ ) [-10.1 (SD 13.6) $\mathrm{mmol} / \mathrm{mol}]$ in the UUS:5-8 group, compared with -0.33 (SD 0.80\%) [-3.63 (SD 8.8$) \mathrm{mmol} / \mathrm{mol}$ ] in the UUS:0-4 group $(P=.049)$. Reductions in mean $\mathrm{HbA}_{1 \mathrm{c}}$ levels were greater in the UUS:5-8 group than in the UUS:0-4 group at 3 months [ -1.0 (SD $1.40 \%$ ) vs -0.37 (SD 0.73\%); $P=.02]$ and at 6 months [-0.99 (SD 1.09\%) vs -0.32 (SD 1.08\%); $P=.01]$. 
Figure 1. Glycated hemoglobin $\left(\mathrm{HbA}_{1 \mathrm{c}}\right)$ levels for the 12-month study period in the UUS:0-4 group and UUS:5-8 group. Repeated-measures ANOVA revealed significant differences between the groups over 12 months $(P=.011)$. The last observation carried forward $(\mathrm{LOCF})$ imputation method was used. UUS: user utility score.

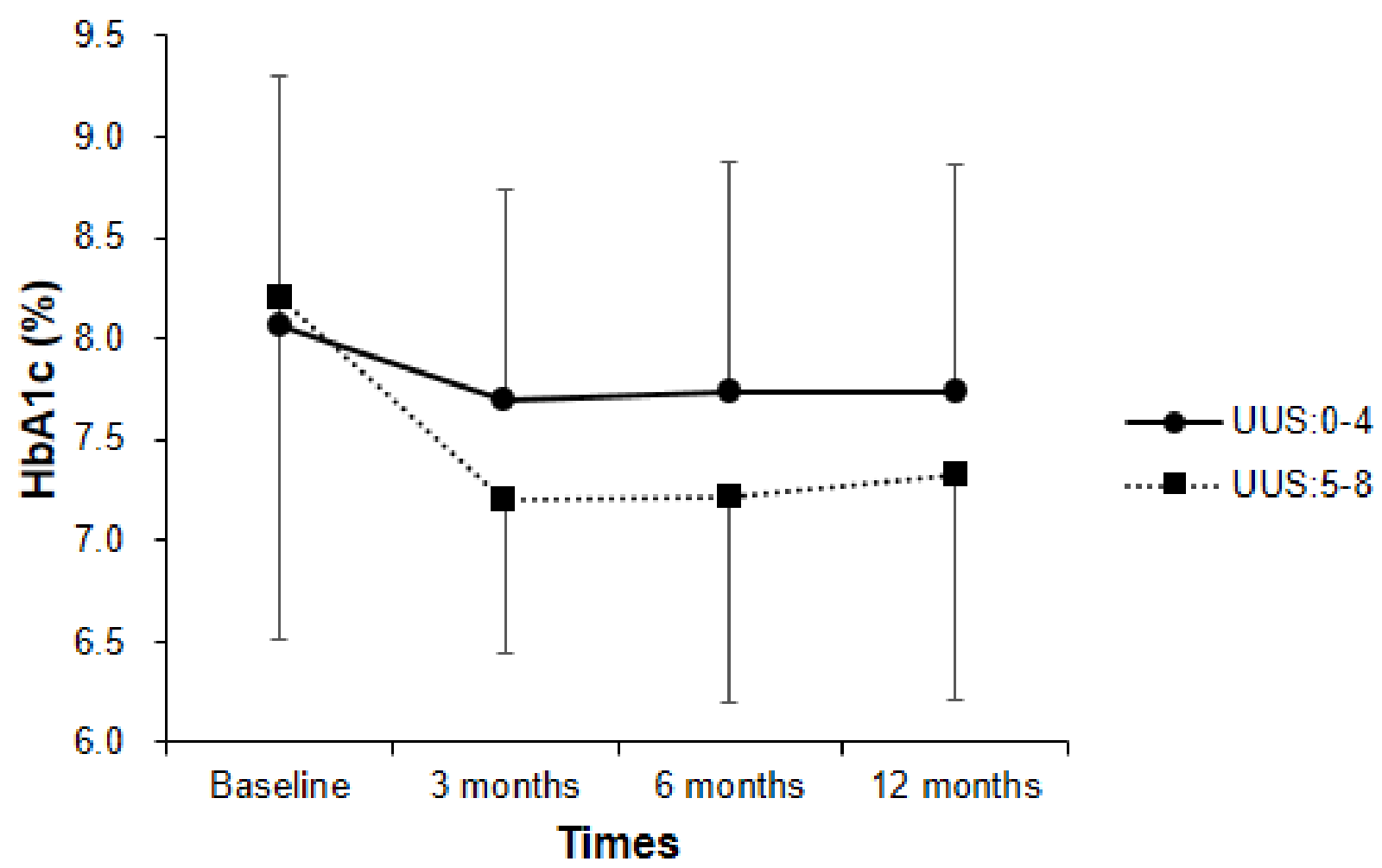

Table 2. Changes from baseline in glycated hemoglobin $\left(\mathrm{HbA}_{1 \mathrm{c}}\right)$ at 3, 6, and 12 months in the UUS:0-4 group and UUS:5-8 group.

\begin{tabular}{|c|c|c|c|}
\hline $\mathrm{HbA}_{1 \mathrm{c}}$ at each time point & UUS $^{\mathrm{a}}: 0-4$ & UUS:5-8 & $P$ value $^{\mathrm{b}}$ \\
\hline \multicolumn{4}{|c|}{3 months from baseline ( $n=72)$} \\
\hline Participants, n (\%) & $38(53)$ & $34(47)$ & \\
\hline $\mathrm{HbA}_{1 \mathrm{c}} \%$, mean $(\mathrm{SD})$ & $-0.37(0.73)$ & $-1.0(1.40)$ & .018 \\
\hline \multicolumn{4}{|c|}{6 months from baseline $(n=72)$} \\
\hline Participants, n (\%) & $38(53)$ & $34(47)$ & \\
\hline $\mathrm{HbA}_{1 \mathrm{c}} \%$, mean $(\mathrm{SD})$ & $-0.32(1.08)$ & $-0.99(1.09)$ & .013 \\
\hline \multicolumn{4}{|c|}{12 months from baseline $(n=54)$} \\
\hline Participants, n (\%) & $23(43)$ & $31(57)$ & \\
\hline $\mathrm{HbA}_{1 \mathrm{c}} \%$, mean $(\mathrm{SD})$ & $-0.33(0.80)$ & $-0.92(1.24)$ & .049 \\
\hline
\end{tabular}

${ }^{\mathrm{a}}$ UUS: user utility score.

${ }^{\mathrm{b}} P$ values were derived from the Student $t$-test.

Table 3 shows the association of UUS for the first 3 months with changes in $\mathrm{HbA}_{1 \mathrm{c}}$ at 3, 6, and 12 months. Simple linear regression analysis revealed a significant association of UUS with changes in $\mathrm{HbA}_{1 \mathrm{c}}$ at 3, 6, and 12 months in the LOCF analysis. In multivariable linear regression analyses, after adjustment for age, sex, BMI, systolic blood pressure, LDL cholesterol, $\mathrm{HbA}_{1 \mathrm{c}}$ at baseline, diabetes duration, cigarette smoking, alcohol consumption, and ADS score (model 3), UUS was significantly associated with changes in $\mathrm{HbA}_{1 \mathrm{c}}$ at 3,6 , and
12 months; the regression coefficients were -0.113 (SD 0.040; $P=.006$ ), -0.143 (SD 0.045; $P=.002$ ), and -0.136 (SD 0.052; $P=.011$ ), respectively. In model 3 , the result was still significant under the Bonferroni adjustment for multiple comparisons between 3 points of time. In addition, UUS was inversely associated with reduction rates of $\mathrm{HbA}_{1 \mathrm{c}}$ at 3,6 , and 12 months; the regression coefficients were -2.70 (SD 1.24; $P=.03$ ), -3.35 (SD 1.37; $P=.02$ ), and -3.19 (SD $1.59 ; P=.049$ ), respectively (Table 4). 
Table 3. Association of user utility score (UUS) with change in glycated hemoglobin $\left(\mathrm{HbA}_{1 \mathrm{c}}\right)$ by multivariable linear regression analyses.

\begin{tabular}{|c|c|c|c|c|c|c|}
\hline \multirow[t]{2}{*}{ UUS } & \multicolumn{2}{|c|}{3 months from baseline } & \multicolumn{2}{|l|}{6 months from baseline } & \multicolumn{2}{|c|}{12 months from baseline ${ }^{\mathrm{a}}$} \\
\hline & $\beta\left(\mathrm{SE}^{\mathrm{b}}\right)$ & $P$ value ${ }^{\mathrm{c}}$ & $\beta(\mathrm{SE})$ & $P$ value & $\beta(\mathrm{SE})$ & $P$ value \\
\hline Crude & $-0.121(0.055)$ & .031 & $-0.125(0.054)$ & .023 & $-0.124(0.048)$ & .011 \\
\hline Model $1^{\mathrm{d}}$ & $-0.119(0.057)$ & .042 & $-0.127(0.057)$ & .028 & $-0.128(0.050)$ & .012 \\
\hline Model $2^{\mathrm{e}}$ & $-0.100(0.037)$ & .009 & $-0.109(0.043)$ & .014 & $-0.108(0.051)$ & .038 \\
\hline Model $3^{\mathrm{f}}$ & $-0.113(0.040)$ & .006 & $-0.143(0.045)$ & .002 & $-0.136(0.052)$ & .011 \\
\hline
\end{tabular}

${ }^{\mathrm{a}}$ The last observation carried forward (LOCF) imputation method was used.

${ }^{\mathrm{b}} \mathrm{SE}$ : standard error.

${ }^{\mathrm{c}} P$ values in multiple regression models are significant at $P<.05$. $P$ values after Bonferroni correction are significant at $P<.016$.

${ }^{\mathrm{d}}$ Model 1 was adjusted for age and sex.

${ }^{\mathrm{e}}$ Model 2 was adjusted for age, sex, BMI, systolic blood pressure, $\mathrm{LDL}$ cholesterol, $\mathrm{HbA}_{1 \mathrm{c}}$ at baseline, and diabetes duration.

${ }^{\mathrm{f}}$ Model 3 was adjusted for age, sex, BMI, systolic blood pressure, LDL cholesterol, $\mathrm{HbA}_{1 \mathrm{c}}$ at baseline, diabetes duration, cigarette smoking, alcohol consumption, and the Appraisal of Diabetes Scale (ADS) score.

Table 4. Association of user utility score (UUS) with glycated hemoglobin $\left(\mathrm{HbA}_{1 \mathrm{c}}\right)$ reduction rate by linear regression analyses.

\begin{tabular}{llc}
\hline UUS at each time point & $\beta\left(\mathrm{SE}^{\mathrm{a}}\right)$ & $P$ value $^{\mathrm{b}}$ \\
\hline 3 months from baseline & $-2.70(1.24)$ & .033 \\
6 months from baseline & $-3.35(1.37)$ & .017 \\
12 months from baseline & $-3.19(1.59)$ & .049 \\
\hline
\end{tabular}

${ }^{\mathrm{a}} \mathrm{SE}$ : standard error.

${ }^{\mathrm{b}}$ Regression coefficients $(\beta)$ and $P$ values were derived from linear regression analysis.

${ }^{\mathrm{c}}$ The last observation carried forward (LOCF) imputation method was used.

\section{UUS and Health Outcomes}

Table 5 shows changes in health outcomes from baseline at 3 , 6, and 12 months in the UUS:0-4 group and UUS:5-8 group. At 3 months, HDL cholesterol levels between the UUS:0-4 and UUS:5-8 groups were -2.03 (SD 7.02) $\mathrm{mg} / \mathrm{dL}$ and 1.48 (SD $7.33) \mathrm{mg} / \mathrm{dL}$, respectively $(P=.04)$. There were no significant differences in the changes in BMI, systolic blood pressure, HDL cholesterol, and SDSCA and ADS scores, after Bonferroni adjustment, between the 2 groups at 3, 6, and 12 months. There was a suggestion that the high UUS was more beneficial for HDL cholesterol, with the $P$ value indicating a significant difference on the basis of the conventional threshold for significance but not the Bonferroni-adjusted threshold. 
Table 5. Changes in biochemical parameters and questionnaires over 12 months in the UUS:0-4 group and UUS:5-8 group.

\begin{tabular}{|c|c|c|c|c|c|c|c|c|c|}
\hline \multirow[t]{2}{*}{ Variable, mean (SD) } & \multicolumn{3}{|c|}{3 months from baseline $(n=72)$} & \multicolumn{3}{|c|}{6 months from baseline $(n=72)$} & \multicolumn{3}{|c|}{12 months from baseline $(\mathrm{n}=54)$} \\
\hline & $\begin{array}{l}\text { UUS:0-4 } \\
(\mathrm{n}=38)\end{array}$ & $\begin{array}{l}\text { UUS:5-8 } \\
(\mathrm{n}=34)\end{array}$ & $P$ value $^{\mathrm{a}}$ & $\begin{array}{l}\text { UUS:0-4 } \\
(\mathrm{n}=38)\end{array}$ & $\begin{array}{l}\text { UUS:5-8 } \\
(\mathrm{n}=34)\end{array}$ & $P$ value & $\begin{array}{l}\text { UUS:0-4 } \\
(n=23)\end{array}$ & $\begin{array}{l}\text { UUS:5-8 } \\
(\mathrm{n}=31)\end{array}$ & $P$ value \\
\hline Body mass index, $\mathrm{kg} / \mathrm{m}^{2}$ & $-0.25(0.67)$ & $-0.42(0.85)$ & .36 & $-0.41(0.82)$ & $-0.32(0.93)$ & .68 & $0.01(0.92)$ & $0.04(1.16)$ & .89 \\
\hline $\begin{array}{l}\text { Systolic blood pressure, } \\
\mathrm{mmHg}\end{array}$ & $-15.45(16.82)$ & $\begin{array}{l}-14.38 \\
(16.14)\end{array}$ & .79 & $\begin{array}{l}-17.29 \\
(16.27)\end{array}$ & $\begin{array}{l}-16.29 \\
(14.15)\end{array}$ & .78 & $\begin{array}{l}-8.01 \\
(16.77)\end{array}$ & $\begin{array}{l}-7.32 \\
(13.82)\end{array}$ & .87 \\
\hline $\begin{array}{l}\text { Diastolic blood pressure, } \\
\mathrm{mmHg}\end{array}$ & $-7.34(10.37)$ & $-7.26(8.87)$ & .97 & $\begin{array}{l}-9.84 \\
(10.22)\end{array}$ & $-6.82(8.46)$ & .18 & $-1.91(9.65)$ & $-2.97(7.61)$ & .66 \\
\hline Total cholesterol, mg/dL & $3.56(32.44)$ & $\begin{array}{l}10.82 \\
(26.50)\end{array}$ & .31 & $\begin{array}{l}-1.15 \\
(31.80)\end{array}$ & $3.79(32.15)$ & .52 & $6.30(43.66)$ & $\begin{array}{l}-1.74 \\
(38.18)\end{array}$ & .53 \\
\hline Triglyceride, $\mathrm{mg} / \mathrm{dL}$ & $3.87(72.91)$ & $\begin{array}{l}-17.76 \\
(42.42)\end{array}$ & .14 & $\begin{array}{l}-5.03 \\
(78.00)\end{array}$ & $\begin{array}{l}-8.30 \\
(51.79)\end{array}$ & .84 & $\begin{array}{l}25.39 \\
(90.86)\end{array}$ & $\begin{array}{l}-6.65 \\
(60.32)\end{array}$ & .14 \\
\hline HDL cholesterol, mg/dL & $-2.03(7.02)$ & $1.48(7.33)$ & .04 & $0.28(6.48)$ & $2.61(7.37)$ & .16 & $0.43(7.09)$ & $4.61(8.55)$ & .06 \\
\hline LDL cholesterol, mg/dL & $4.75(29.84)$ & $\begin{array}{l}12.78 \\
(24.80)\end{array}$ & .22 & $\begin{array}{l}-0.49 \\
(28.75)\end{array}$ & $2.85(28.82)$ & .63 & $1.33(38.63)$ & $\begin{array}{l}-5.07 \\
(35.29)\end{array}$ & .53 \\
\hline \multicolumn{10}{|c|}{ Summary of Diabetes Self-care Activities (SDSCA) questionnaire, mean (SD) } \\
\hline Diet total & $\mathrm{N} / \mathrm{A}^{\mathrm{b}}$ & N/A & N/A & $1.24(7.05)$ & $1.47(7.82)$ & .894 & $2.23(6.87)$ & $1.35(5.35)$ & .61 \\
\hline Exercise & N/A & N/A & N/A & $0.56(3.79)$ & $0.74(3.06)$ & .83 & $0.58(2.69)$ & $1.36(3.14)$ & .34 \\
\hline $\begin{array}{l}\text { Blood glucose test- } \\
\text { ing }\end{array}$ & N/A & N/A & N/A & $2.29(5.56)$ & $4.15(6.11)$ & .38 & $0.32(4.94)$ & $1.13(5.92)$ & .60 \\
\hline Foot care & N/A & N/A & N/A & $3.66(5.23)$ & $2.79(5.47)$ & .50 & $3.59(5.79)$ & $2.97(4.35)$ & .66 \\
\hline $\begin{array}{l}\text { Appraisal of Diabetes } \\
\text { Scale (ADS) total }\end{array}$ & N/A & N/A & N/A & $-0.79(4.82)$ & $-1.5(4.97)$ & .54 & $-1.41(4.55)$ & $-1.81(3.75)$ & .73 \\
\hline
\end{tabular}

${ }^{\text {a }} P$ values were derived from the Student $t$ test.

${ }^{\mathrm{b}} \mathrm{N} / \mathrm{A}$ : not applicable.

\section{Discussion}

\section{Principal Findings}

In this study, we found that UUS for the first 3 months was associated with changes in $\mathrm{HbA}_{1 \mathrm{c}}$ during a 12-month follow-up period. When we divided participants into 2 groups based on UUS for the first 3 months, the high UUS group resulted in greater decreases in $\mathrm{HbA}_{1 \mathrm{c}}$ over 12 months compared with the low UUS group. Multivariable linear regression analyses revealed that UUS for the first 3 months was significantly inversely associated with changes in $\mathrm{HbA}_{1 \mathrm{c}}$ at 3,6 , and 12 months. These results indicated that initial active engagement for the first 3 months with a mobile health application was associated with improved glycemic control over the whole study period.

Patient engagement with a mobile health application could be a significant factor contributing to diabetes self-management $[28,29]$. Research showed that initial engagement with a mobile health application is closely related to long-term engagement [30]. We previously reported that initial active engagement was significantly correlated with improved glycemic control [31]. In this study, UUS gradually decreased over 12 months but was consistently higher in the initial high UUS group than in the low UUS group. In addition, more participants were lost to follow-up in the low UUS group $(15 / 38,39 \%)$ than in the high
UUS group $(3 / 34,9 \%)$ at 12 months. High UUS in the beginning was critical. We found that initial active engagement could predict improved glycemic control during a 12-month follow-up period. Therefore, initial strategies to enhance patient engagement from the beginning in the low UUS group are necessary.

We developed the UUS as a tool to measure user utility by analyzing and scoring uploaded data, including blood glucose testing, dietary and exercise records, and message reading. The results of this study reinforce findings from previous mobile health investigations that have shown the benefits of lifestyle interventions with appropriate blood glucose testing, adoption of a healthy diet and physical activity, and reading of text messages on diabetes outcomes [31-36]. Meanwhile, patient engagement is related to other factors such as medications, foot care, and changes in weight [37]. To quantify patient engagement, scoring systems should take into account that each factor in UUS varies in priority and importance. Our findings will act as a cornerstone for other studies exploring effective UUS components and the optimal threshold of each component for predicting improved health outcomes.

In addition, we found no difference in baseline $\mathrm{HbA}_{1 \mathrm{c}}$, BMI, blood pressure, HDL cholesterol, LDL cholesterol, SDSCA, and ADS to assess diabetes self-management between groups divided according to UUS. There was no relationship of UUS with blood pressure, lipid profile, or diabetes self-management. 
Although the high UUS group achieved greater improvement in HDL cholesterol at 3 months than the low UUS group, this difference was not statistically significant. Regular exercise increases HDL cholesterol levels [38,39], and so it would be interesting to evaluate the association between patient engagement and HDL cholesterol. Further randomized controlled trials are needed to investigate the relationship between patient engagement and health outcomes among patients with type 2 diabetes. However, UUS was not related to cardiovascular risk factors such as LDL, blood pressure, and BMI. The results support the concept that UUS could be a useful tool for predicting improved glycemic control in diabetes management using the TMC system.

Chronic diseases such as diabetes that require ongoing medical care can benefit from the integration of digital health technology-based tools [16]. Digital health technology in diabetes care offers the opportunity to track and visualize data regarding parameters such as blood glucose testing, dietary habits, physical activity, and text messages and has been promoted to support self-management and facilitate lifestyle changes $[11,40,41]$. We found that UUS with behavioral components was correlated with changes in $\mathrm{HbA}_{1 \mathrm{c}}$ in a 12-month follow-up evaluation $(\mathrm{r}=-0.136, P=.01)$. According to the SDSCA, the frequency of blood glucose testing was higher in patients with a high UUS score than in those with a low UUS score $(P=.09)$. This seems to be the most important contributing factor to the results of this study. Interestingly, however, individual components of UUS were not correlated with changes in $\mathrm{HbA}_{1 \mathrm{c}}$. This study did not show that patient engagement was not associated with each individual behavioral component.

Patient engagement assessment tools could be useful for evaluating their own diabetes self-management [42]. Remmers et al [43] examined the association of patient activation measure (PAM) scores with health outcomes among patients with diabetes and found that PAM scores could be used to identify patients at risk for poorer health outcomes. Previous studies that found differences between patients who engage and those who do not engage in digital health interventions demonstrated the importance of patient engagement to glycemic control [39]. Our results support the idea that although digital technology will not provide a solution for everyone, the use of mobile health technology tools, when applied appropriately, could improve the health outcomes of patients with diabetes [44]. Moreover, long-term management is critical because people usually participate actively in the beginning, but their interest disappears. We suggest that the optimal use of UUS should be individualized based on the clinical needs of individual patients and the requirements of care providers. Further investigation regarding how to motivate participants toward engaging in this digital health system is needed.

\section{Limitations}

There were several limitations to the study. First, although the relationship between UUS and glycemic control was statistically significant, the post-hoc analysis study design was one limitation. It is important to adjust for confounding variables, potentially influencing patient outcomes. The use of digital health tools may be influenced by education level and social deprivation, among other factors. Although these variables were not included as covariates in the model, any response bias is likely minimal. Second, UUS consisted of only 4 behavioral components and was calculated retrospectively. However, we used a holdout set for validation and introduced UUS to project user participation and effects on glycemic control. Finally, the study had a small sample size, and values for $25 \%$ (18/72) of participants were missing at 12 months. Regression analysis of the association between UUS and $\mathrm{HbA}_{1 \mathrm{c}}$ was performed using the LOCF approach to examine trends over time, rather than focusing simply on the endpoint. This imputation might lead to biased results. However, for the comparison of $\mathrm{HbA}_{1 \mathrm{c}}$ between the UUS groups, data were analyzed without applying LOCF, which revealed a significant group difference. Larger prospective long-term studies are needed to assess the UUS's utility in a real-world setting.

\section{Conclusions}

In this study, we developed the UUS as a patient engagement measure with behavioral components from an individual perspective. UUS in the beginning was associated with changes in $\mathrm{HbA}_{1 \mathrm{c}}$ over the study period of the TMC system and could be a useful tool for predicting improved glycemic control in diabetes self-management through mobile health interventions. Our results provide insight into the importance of patient engagement in mobile diabetes intervention, and further studies to explore the optimal measure of patient engagement for diabetes management are needed.

\section{Acknowledgments}

The authors would like to express their appreciation to Kangbuk Samsung Hospital for their assistance with patient recruitment and data collection. The initial project was funded by Samsung Fire and Marine Insurance Company. This funder had no role in the design, conduct, or analysis of the trial.

\section{Authors' Contributions}

MKL and DYL contributed to the study design and data analysis. MKL drafted and edited the manuscript. CYP provided supervision and revised the manuscript. MKL, DYL, HYA, and CYP participated in the analytic discussion of the results. All authors have read and approved the final manuscript.

\section{Conflicts of Interest}

None declared. 


\section{References}

1. Baik I. Projection of Diabetes Prevalence in Korean Adults for the Year 2030 Using Risk Factors Identified from National Data. Diabetes Metab J 2019;43(1):90. [doi: 10.4093/dmj.2018.0043]

2. Song SO, Lee Y, Kim DW, Song YD, Nam JY, Park KH, et al. Trends in Diabetes Incidence in the Last Decade Based on Korean National Health Insurance Claims Data. Endocrinol Metab 2016;31(2):292. [doi: 10.3803/enm.2016.31.2.292]

3. American Diabetes Association. Abridged for Primary Care Providers. Clin Diabetes 2018 Dec 17;37(1):11-34. [doi: 10.2337/cd18-0105]

4. Seuring T, Archangelidi O, Suhrcke M. The Economic Costs of Type 2 Diabetes: A Global Systematic Review. Pharmacoeconomics 2015 Aug 19;33(8):811-831 [FREE Full text] [doi: 10.1007/s40273-015-0268-9] [Medline: 25787932]

5. Powell P, Corathers S, Raymond J, Streisand R. New approaches to providing individualized diabetes care in the 21st century. Curr Diabetes Rev 2015 Jul 29;11(4):222-230 [FREE Full text] [doi: 10.2174/1573399811666150421110316] [Medline: 25901504]

6. Pal K, Dack C, Ross J, Michie S, May C, Stevenson F, et al. Digital Health Interventions for Adults With Type 2 Diabetes: Qualitative Study of Patient Perspectives on Diabetes Self-Management Education and Support. J Med Internet Res 2018 Jan 29;20(2):e40 [FREE Full text] [doi: 10.2196/jmir.8439] [Medline: 29463488]

7. Powers MA, Bardsley J, Cypress M, Duker P, Funnell MM, Hess Fischl A, et al. Diabetes Self-management Education and Support in Type 2 Diabetes: A Joint Position Statement of the American Diabetes Association, the American Association of Diabetes Educators, and the Academy of Nutrition and Dietetics. Diabetes Care 2015 Jul 05;38(7):1372-1382. [doi: 10.2337/dc15-0730] [Medline: 26048904]

8. Asif M. The prevention and control the type-2 diabetes by changing lifestyle and dietary pattern. J Educ Health Promot 2014;3(1):1 [FREE Full text] [doi: 10.4103/2277-9531.127541] [Medline: 24741641]

9. Chen L, Pei J, Kuang J, Chen H, Chen Z, Li Z, et al. Effect of lifestyle intervention in patients with type 2 diabetes: a meta-analysis. Metabolism 2015 Feb;64(2):338-347 [FREE Full text] [doi: 10.1016/j.metabol.2014.10.018] [Medline: 25467842]

10. Babazadeh T, Dianatinasab M, Daemi A, Nikbakht HA, Moradi F, Ghaffari-Fam S. Association of Self-Care Behaviors and Quality of Life among Patients with Type 2 Diabetes Mellitus: Chaldoran County, Iran. Diabetes Metab J 2017 Dec;41(6):449-456 [FREE Full text] [doi: 10.4093/dmj.2017.41.6.449] [Medline: 29272083]

11. Iyengar V, Wolf A, Brown A, Close K. Challenges in Diabetes Care: Can Digital Health Help Address Them? Clin Diabetes 2016 Jul 22;34(3):133-141 [FREE Full text] [doi: 10.2337/diaclin.34.3.133] [Medline: 27621530]

12. Beck J, Greenwood DA, Blanton L, Bollinger ST, Butcher MK, Condon JE, 2017 Standards Revision Task Force. 2017 National Standards for Diabetes Self-Management Education and Support. Diabetes Educ 2018 Feb;44(1):35-50. [doi: 10.1177/0145721718754797] [Medline: 29346744]

13. Diabetes Association A. 7. Diabetes Technology:. Dia Care 2018 Dec 17;42(Supplement 1):S71-S80. [doi: 10.2337/dc19-s007]

14. Swan M. Health 2050: The Realization of Personalized Medicine through Crowdsourcing, the Quantified Self, and the Participatory Biocitizen. J Pers Med 2012 Sep 12;2(3):93-118 [FREE Full text] [doi: 10.3390/jpm2030093] [Medline: 25562203]

15. Izahar S, Lean QY, Hameed MA, Murugiah MK, Patel RP, Al-Worafi YM, et al. Content Analysis of Mobile Health Applications on Diabetes Mellitus. Front Endocrinol (Lausanne) 2017;8:318 [FREE Full text] [doi: 10.3389/fendo.2017.00318] [Medline: 29230195]

16. Kaufman N, Khurana I. Using Digital Health Technology to Prevent and Treat Diabetes. Diabetes Technol Ther 2016 Feb;18 Suppl 1(S1):S56-S68 [FREE Full text] [doi: 10.1089/dia.2016.2506] [Medline: 26836430]

17. Simacek KF, Nelson T, Miller-Baldi M, Bolge SC. Patient engagement in type 2 diabetes mellitus research: what patients want. PPA 2018 Apr;Volume 12:595-606. [doi: 10.2147/ppa.s159707]

18. Lee DY, Park J, Choi D, Ahn H, Park S, Park C. The effectiveness, reproducibility, and durability of tailored mobile coaching on diabetes management in policyholders: A randomized, controlled, open-label study. Sci Rep 2018 Feb 26;8(1):3642 [FREE Full text] [doi: 10.1038/s41598-018-22034-0] [Medline: 29483559]

19. Polonsky WH, Fisher L. Self-Monitoring of Blood Glucose in Noninsulin-Using Type 2 Diabetic Patients: Right answer, but wrong question: self-monitoring of blood glucose can be clinically valuable for noninsulin users. Diabetes Care 2012 Dec 20;36(1):179-182. [doi: $10.2337 / \mathrm{dc} 12-0731$ ]

20. Porter J, Huggins CE, Truby H, Collins J. The Effect of Using Mobile Technology-Based Methods That Record Food or Nutrient Intake on Diabetes Control and Nutrition Outcomes: A Systematic Review. Nutrients 2016 Dec 17;8(12) [FREE Full text] [doi: 10.3390/nu8120815] [Medline: 27999302]

21. Huang X, Pan J, Chen D, Chen J, Chen F, Hu T. Efficacy of lifestyle interventions in patients with type 2 diabetes: A systematic review and meta-analysis. Eur J Intern Med 2016 Jan;27:37-47. [doi: 10.1016/j.ejim.2015.11.016] [Medline: 26655787]

22. Sahin C, Courtney KL, Naylor PJ, E Rhodes R. Tailored mobile text messaging interventions targeting type 2 diabetes self-management: A systematic review and a meta-analysis. Digit Health 2019;5:2055207619845279 [FREE Full text] [doi: 10.1177/2055207619845279] [Medline: $\underline{31041110]}$ 
23. Lee D, Yoo S, Min K, Park C. Effect of Voluntary Participation on Mobile Health Care in Diabetes Management: Randomized Controlled Open-Label Trial. JMIR Mhealth Uhealth 2020 Sep 18;8(9):e19153 [FREE Full text] [doi: 10.2196/19153] [Medline: $\underline{32945775}$ ]

24. Choi EJ, Nam M, Kim SH, Park CG, Toobert DJ, Yoo JS, et al. Psychometric properties of a Korean version of the summary of diabetes self-care activities measure. Int J Nurs Stud 2011 Mar;48(3):333-337. [doi: 10.1016/j.ijnurstu.2010.08.007] [Medline: 20950807]

25. Lee E, Lee YW, Lee K, Nam M, Kim YS, Han SJ. A Korean version of the Appraisal of Diabetes Scale (ADS-K): psychometric evaluation with a population of Koreans with type 2 diabetes. J Transcult Nurs 2015 May 29;26(3):270-278. [doi: 10.1177/1043659614524793] [Medline: 24782147]

26. Toobert DJ, Hampson SE, Glasgow RE. The summary of diabetes self-care activities measure: results from 7 studies and a revised scale. Diabetes Care 2000 Jul 01;23(7):943-950 [FREE Full text] [doi: 10.2337/diacare.23.7.943] [Medline: 10895844]

27. Carey MP, Jorgensen RS, Weinstock RS, Sprafkin RP, Lantinga LJ, Carnrike CLM, et al. Reliability and validity of the Appraisal of Diabetes Scale. J Behav Med 1991 Feb;14(1):43-50. [doi: 10.1007/bf00844767]

28. Barello S, Graffigna G, Vegni E. Patient engagement as an emerging challenge for healthcare services: mapping the literature. Nurs Res Pract 2012;2012:905934 [FREE Full text] [doi: 10.1155/2012/905934] [Medline: 23213497]

29. Serrano-Gil M, Jacob S. Engaging and empowering patients to manage their type 2 diabetes, Part I: a knowledge, attitude, and practice gap? Adv Ther 2010 Jun;27(6):321-333. [doi: 10.1007/s12325-010-0034-5] [Medline: 20552306]

30. Lee K, Kwon H, Lee B, Lee G, Lee JH, Park YR, et al. Effect of self-monitoring on long-term patient engagement with mobile health applications. PLoS One 2018 Jul 26;13(7):e0201166 [FREE Full text] [doi: 10.1371/journal.pone.0201166] [Medline: $\underline{30048546}$ ]

31. Lee M, Lee K, Yoo S, Park C. Impact of initial active engagement in self-monitoring with a telemonitoring device on glycemic control among patients with type 2 diabetes. Sci Rep 2017 Jun 20;7(1):3866 [FREE Full text] [doi: 10.1038/s41598-017-03842-2] [Medline: 28634381]

32. Anton SD, LeBlanc E, Allen HR, Karabetian C, Sacks F, Bray G, et al. Use of a computerized tracking system to monitor and provide feedback on dietary goals for calorie-restricted diets: the POUNDS LOST study. J Diabetes Sci Technol 2012 Sep 01;6(5):1216-1225 [FREE Full text] [doi: 10.1177/193229681200600527] [Medline: 23063049]

33. Wu X, Guo X, Zhang Z. The Efficacy of Mobile Phone Apps for Lifestyle Modification in Diabetes: Systematic Review and Meta-Analysis. JMIR Mhealth Uhealth 2019 Jan 15;7(1):e12297 [FREE Full text] [doi: 10.2196/12297] [Medline: $\underline{30664494]}$

34. Quinn CC, Shardell MD, Terrin ML, Barr EA, Ballew SH, Gruber-Baldini AL. Cluster-randomized trial of a mobile phone personalized behavioral intervention for blood glucose control. Diabetes Care 2011 Sep 25;34(9):1934-1942 [FREE Full text] [doi: 10.2337/dc11-0366] [Medline: 21788632]

35. Travasso C. Lifestyle advice by text messages helps prevent type 2 diabetes in high risk men. BMJ 2013 Sep 23;347(sep23 1):f5750-f5750. [doi: 10.1136/bmj.f5750] [Medline: 24062188]

36. Yoon K, Kim H. A short message service by cellular phone in type 2 diabetic patients for 12 months. Diabetes Res Clin Pract 2008 Feb;79(2):256-261. [doi: 10.1016/j.diabres.2007.09.007] [Medline: 17988756]

37. Hartz A, Kent S, James P, Xu Y, Kelly M, Daly J. Factors that influence improvement for patients with poorly controlled type 2 diabetes. Diabetes Res Clin Pract 2006 Dec;74(3):227-232. [doi: 10.1016/j.diabres.2006.03.023] [Medline: 16723163]

38. Kodama S, Tanaka S, Saito K, Shu M, Sone Y, Onitake F, et al. Effect of aerobic exercise training on serum levels of high-density lipoprotein cholesterol: a meta-analysis. Arch Intern Med 2007 May 28;167(10):999-1008. [doi: 10.1001/archinte.167.10.999] [Medline: 17533202]

39. Lee S, Kim Y, Kuk JL. What Is the Role of Resistance Exercise in Improving the Cardiometabolic Health of Adolescents with Obesity? J Obes Metab Syndr 2019 Jun 30;28(2):76-91 [FREE Full text] [doi: 10.7570/jomes.2019.28.2.76] [Medline: $\underline{31294340]}$

40. Cahn A, Akirov A, Raz I. Digital health technology and diabetes management. J Diabetes 2018 Jan;10(1):10-17. [doi: 10.1111/1753-0407.12606] [Medline: 28872765]

41. Quinn CC, Butler EC, Swasey KK, Shardell MD, Terrin MD, Barr EA, et al. Mobile Diabetes Intervention Study of Patient Engagement and Impact on Blood Glucose: Mixed Methods Analysis. JMIR Mhealth Uhealth 2018 Feb 02;6(2):e31 [FREE Full text] [doi: 10.2196/mhealth.9265] [Medline: 29396389]

42. Graffigna G, Barello S, Libreri C, Bosio CA. How to engage type-2 diabetic patients in their own health management: implications for clinical practice. BMC Public Health 2014 Jun 25;14(1):648 [FREE Full text] [doi: 10.1186/1471-2458-14-648] [Medline: 24966036]

43. Remmers C, Hibbard J, Mosen DM, Wagenfield M, Hoye RE, Jones C. Is patient activation associated with future health outcomes and healthcare utilization among patients with diabetes? J Ambul Care Manage 2009;32(4):320-327. [doi: 10.1097/JAC.0b013e3181ba6e77] [Medline: 19888008 ]

44. Wiederhold BK, Riva G, Graffigna G. Ensuring the best care for our increasing aging population: health engagement and positive technology can help patients achieve a more active role in future healthcare. Cyberpsychol Behav Soc Netw 2013 Jun;16(6):411-412. [doi: 10.1089/cyber.2013.1520] [Medline: 23751102] 


\section{Abbreviations}

ADS: Appraisal of Diabetes Scale

BMI: body mass index

$\mathbf{H b A}_{1 \mathbf{c}}$ : glycated hemoglobin

HDL: high-density lipoprotein

LDL: low-density lipoprotein

LOCF: last observation carried forward

PAM: patient activation measure

SDSCA: Summary of Diabetes Self-Care Activities questionnaire

TMC: tailored mobile coaching

UUS: user utility score

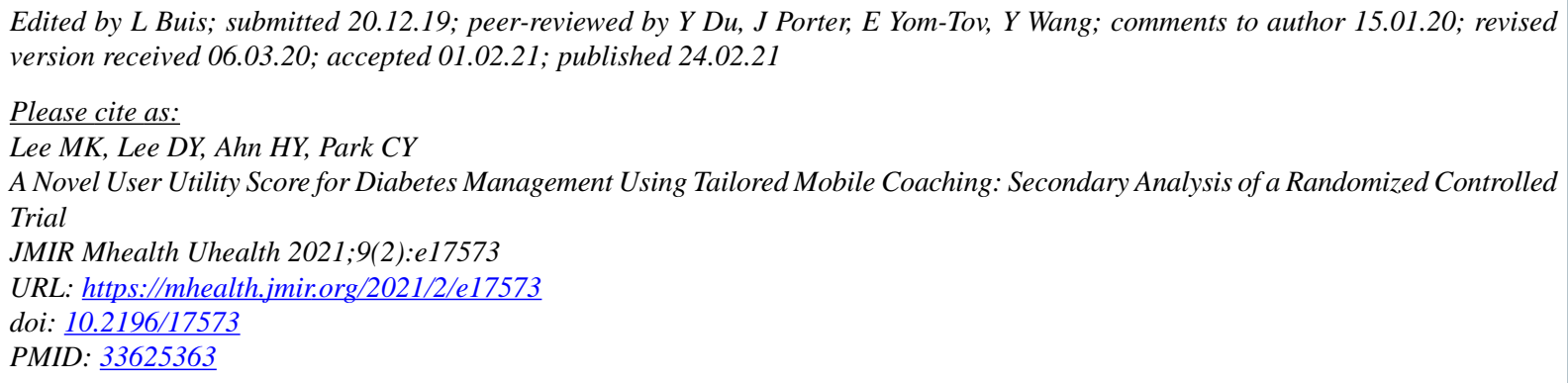

CMin-Kyung Lee, Da Young Lee, Hong-Yup Ahn, Cheol-Young Park. Originally published in JMIR mHealth and uHealth (http://mhealth.jmir.org), 24.02.2021. This is an open-access article distributed under the terms of the Creative Commons Attribution License (https://creativecommons.org/licenses/by/4.0/), which permits unrestricted use, distribution, and reproduction in any medium, provided the original work, first published in JMIR mHealth and uHealth, is properly cited. The complete bibliographic information, a link to the original publication on http://mhealth.jmir.org/, as well as this copyright and license information must be included. 